\title{
The basic helix-loop-helix transcription factor DEC2 inhibits TGF- $\beta$-induced tumor progression in human pancreatic cancer BxPC-3 cells
}

\author{
FUYUKI SATO $^{1}$, HARUKA KAWAMURA ${ }^{1}$, YUNYAN WU ${ }^{1}$, HIROYASU SATO ${ }^{1}$, DAIKI JIN ${ }^{1}$, \\ UJJAL KUMAR BHAWAL ${ }^{2}$, TAKESHI KAWAMOTO ${ }^{3}$, KATSUMI FUJIMOTO ${ }^{3}$, MITSUHIDE NOSHIRO ${ }^{3}$, \\ HIROKO SEINO $^{1}$, SATOMO MOROHASHI ${ }^{1}$, YUKIO KATO ${ }^{3}$ and HIROSHI KIJIMA ${ }^{1}$ \\ ${ }^{1}$ Department of Pathology and Bioscience, Hirosaki University Graduate School of Medicine, Hirosaki 036-8562; \\ ${ }^{2}$ Department of Biochemistry and Molecular Biology, Nihon University School of Dentistry, Matsudo, \\ Chiba 271-8587; ${ }^{3}$ Department of Dental and Medical Biochemistry, Hiroshima University \\ Graduate School of Biomedical Science, Hiroshima 734-8553, Japan
}

Received February 7, 2012; Accepted March 12, 2012

DOI: $10.3892 / \mathrm{ijmm} .2012 .1037$

\begin{abstract}
The basic helix loop helix (bHLH) transcription factor DEC2 is associated with the regulation of apoptosis, circadian rhythm and the response to hypoxia. However, the significance of DEC2 in pancreatic cancer remains unknown. Here, we showed for the first time that DEC2 inhibits the progression of human pancreatic cancer. Human pancreatic cancer BxPC-3 cells were treated with or without transforming growth factor- $\beta$ (TGF- $\beta$ ), siRNA against DEC2, or a combination of TGF- $\beta$ and DEC2 siRNA or DEC2 overexpression. The cells were analyzed by RT-PCR, real-time PCR, western blotting, immunofluorescent staining and ChIP assay. We also performed immunohistochemical analyses of DEC2 expression in surgically-resected pancreatic cancers. The expression of DEC2 was increased in TGF- $\beta$-treated BxPC-3 cells. In the presence of TGF- $\beta$, DEC 2 overexpression decreased the migration and invasion of BxPC-3 cells. Knockdown of DEC2 by siRNA in the presence of TGF- $\beta$ significantly increased the expression and nuclear concentration of slug. We also showed that DEC2 siRNA decreased the binding of DEC2 to the E-box of the slug promoter. Immunohistochemically, little DEC2 was detected in pancreatic cancer tissues, whereas significant amounts were detected in the adjacent non-cancerous pancreatic
\end{abstract}

Correspondence to: Dr Fuyuki Sato, Department of Pathology and Bioscience, Hirosaki University Graduate School of Medicine, Hirosaki 036-8562, Japan

E-mail: fsatodec1dec2@yahoo.co.jp

Abbreviations: DEC2, differentiated embryo chondrocyte 2; TGF- $\beta$, transforming growth factor- $\beta$; PBS, phosphate-buffered saline; siRNA, short interference RNA

Key words: differentiated embryo chondrocyte 2, transforming growth factor- $\beta$, slug, BxPC-3 cells, immunohistochemistry tissues. These results indicate that DEC2 has inhibitory effects against human pancreatic cancer that involve TGF- $\beta$ and slug.

\section{Introduction}

Patients with pancreatic cancer have a poor prognosis with an overall 5-year survival rate of less than 5\% (1). More than $80 \%$ of patients are diagnosed with pancreatic cancer at a locally advanced or metastatic stage (2). Understanding the molecular biology of pancreatic cancer, which can involve migration and invasion may provide insights into the development of novel tumor markers or new therapeutic strategies.

Transforming growth factor- $\beta$ (TGF- $\beta$ ) inhibits cell proliferation and promotes tumor cell motility and invasion $(3,4)$. In comparison with non-tumor pancreatic tissues, pancreatic tumors display increased TGF- $\beta$ expression $(5,6)$. In addition, TGF- $\beta$ treatment has been demonstrated to induce epithelialmesenchymal transition (EMT), which is a key step in the progression of various cancers. During EMT, cells undergo a developmental switch from a polarized, epithelial phenotype to a mesenchymal phenotype (7).

Transcription factors snail and slug are key factors for EMT. They downregulate the expression of various epithelial factors, including E-cadherin, claudins and $\beta$-catenin, and upregulate the expression of mesenchymal markers, including $\mathrm{N}$-cadherin, vimentin and fibronectin $(8,9)$.

Smads also play important roles in the progression of pancreatic cancer and Smad4 mutations are known to be present in more than $50 \%$ of pancreatic cancer cases $(10,11)$. $\mathrm{Smad} 2 / 3$ are considered to be key regulators of pancreatic cancer. TGF- $\beta$ activates the phosphorylation of Smad 2 and Smad 3 and the activated Smad complex binds to target gene promoters and regulates the transcriptional responses to TGF- $\beta$ in the nucleus (12-14).

We have previously shown that tumor necrosis factor- $\alpha$ (TNF- $\alpha$ ), hypoxia, paclitaxel, cisplatin, CLOCK/brain-musclearnt-like-protein (BMAL) 1/2 and polyinosinic-polycytidylic 
acid are upstream factors of the differentiated embryo chondrocyte 2 (DEC2) (BHLHE41/Sharp1), whereas its downstream factors include p53, Bax, Bim, vascular endothelial growth factor (VEGF) and interferon $\beta$ (IFN- $\beta$ ). We have also demonstrated that DEC2 is involved in the regulation of apoptosis, the response to hypoxia and the cell cycle in breast and oral cancer and sarcoma cells (15-21). However, the roles of DEC2 in pancreatic cancer remain unknown. In this study, we focused on the role of DEC2 in pancreatic cancer BxPC-3 cells subjected to TGF- $\beta$ treatment and demonstrated that DEC 2 has inhibitory effects on the tumor progression of $\mathrm{BxPC}-3$ cells.

\section{Materials and methods}

Cell culture and treatment. Human pancreatic cancer BxPC-3 cells were obtained from the American Type Culture Collection (ATCC, Manassas, VA, USA). The cells were cultured in RPMI-1640 medium (Gibco-BRL, Breda, The Netherlands) supplemented with $10 \%$ fetal bovine serum at $37^{\circ} \mathrm{C}$ in a humidified atmosphere of $95 \%$ air and $5 \% \mathrm{CO}_{2}$. For the experiments, the cells were incubated with or without various concentrations of recombinant human TGF- $\beta 1$ (R\&D Systems, Minneapolis, MN, USA) for $24 \mathrm{~h}$.

Knockdown of DEC2 by interference RNA. Short interference RNA (siRNA) against DEC2 was synthesized by Qiagen (Hilden, Germany). The sequences of the sense and anti-sense DEC2 siRNA and the negative control (scrambled) siRNA were described previously (17). For the siRNA transfection experiments, BxPC-3 cells were seeded at $5 \times 10^{4}$ cells per $35-\mathrm{mm}$ well. After $24 \mathrm{~h}$, the cells were transfected with the siRNA using the Lipofectamine RNA iMAX reagent (Invitrogen Life Technologies, Carlsbad, CA, USA). After being transfected, the cells were incubated for $24 \mathrm{~h}$ and subjected to various analyses.

DEC overexpression. DEC1 or DEC2 overexpression was induced using the pcDNA vector as previously described (20). After being transfected, the cells were incubated for $24 \mathrm{~h}$ and subjected to the migration or invasion assay.

Western blotting. The cells were lysed using M-PER lysis buffer (Thermo Scientific, Rockford, IL, USA) and their protein concentrations $(10 \mu \mathrm{g})$ were determined using the bicinchoninic acid (BCA) assay. Their lysates were subjected to SDS-PAGE and the proteins within them were transferred to PVDF membranes (Immobilion P, Millipore, Tokyo, Japan), which were then incubated with antibodies. The ECL, ECL-Plus or ECL-Advance western blotting detection systems (Amersham Pharmacia Biotech, Uppsala, Sweden) were used for detection.

Antibodies. During the western blotting, the membranes were incubated with antibodies specific to DEC2 (1:40,000; Santa Cruz Biotechnology, Inc., Santa Cruz, CA, USA, H-72), DEC1 (1:10,000; Novus Biologicals Inc., Littleton, CO, USA), Smad3 (1:1,000; Epitomics, Inc., Burlingame, CA, USA), pSmad3 (1:6,000; Epitomics, Inc.), slug (1:3,000; Cell Signaling Technology, Inc., Beverley, MA, USA), snail (1:3,000; Cell Signaling Technology, Inc.), vimentin (1:10,000; Epitomics, Inc.), N-cadherin (1:10,000; ECM Biosciences, Versailles,
KY, USA), E-cadherin (1:1000; Takara Bio, Inc.), claudin-1 (1:10,000; Invitrogen Life Technologies), claudin-4 (1:20,000; Invitrogen Life Technologies) and actin (1:30,000; Sigma), followed by horseradish peroxidase-conjugated secondary antibody (Immuno Biological Laboratories Co., Ltd., Fujioka, Gunma, Japan). The Can Get Signal immunoreaction enhancer solution (Toyobo Co., Ltd., Osaka, Japan) or the Immunoshot immunoreaction enhancer solution (Cosmobio Co., Ltd., Tokyo, Japan) was used to dilute the primary antibody.

Real-time polymerase chain reaction $(P C R)$ and reverse transcription-PCR. We prepared three independent RNA samples $(n=3)$ for real-time PCR from the BxPC-3 cells. Total RNA was isolated and first-strand cDNA was synthesized as previously described (20). Real-time PCR was performed using SYBR-Green Master Mix (Invitrogen Life Technologies). The sequences of the primers for DEC1, DEC2 and 18S rRNA used in the real-time PCR and the sizes of their products were previously described (22). The sequences of the primers for slug used for the real-time PCR were as follows: slug-F, 5'-CCATTCCACGCCCAGCTA-3' and R, 5'-TCACTCGCCC CAAAGATGAG-3'. The amplified products of slug were $69 \mathrm{bp}$. The sequences of the primers for DEC1, DEC2 and slug used for the RT-PCR were as follows: DEC1-F, 5'-GTCTGTG AGTCACTCTTCAG-3' and R, 5'-GAGTCTAGTTCTGTTTG AAGG-3'; DEC2-F, 5'-CACCTTTGACGTCTTTGGAG-3' and R, 5'-GAGAGTGGGAATAGATGCAC-3'; slug-F, 5'-GAGCA TTTGCAGACAGGTCA-3' and R, 5'-TGAATTCCATGCTC TTGCAG-3'. The amplified products of DEC1, DEC2 and slug were 534, 502 and 330 bp in length, respectively. The cDNA for DEC1, DEC2 and slug were amplified for up to 28 cycles. The PCR products were separated on $1.5 \%(\mathrm{w} / \mathrm{v})$ agarose gels.

Chromatin immunoprecipitation (ChIP) assay. A ChIP assay was performed using a kit from Millipore, as described previously (16). Primers were designed to amplify a Smad binding element containing a DNA fragment from the DEC2 promoter and their sequences were as follows: human DEC2-F, 5'-GAGGAAGTCGAGAGACCTTAA-3' and R, 5'-CGCCAAAGGTACATGCACCA-3'. Primers were also designed to amplify a DNA fragment containing the E-box in the slug promoter and their sequences were as follows: human slug-F, 5'-AGAGCAGAGCTTGTGCCTTC-3' and R, 5'-GTGGGTTTGCTAATCCAAGG-3'.

Immunofluorescent staining. The cells were seeded in a 4-chamber slide glass and incubated overnight. Then, they were washed with phosphate-buffered saline (PBS) and fixed with $4 \%$ paraformaldehyde for $30 \mathrm{~min}$, before being permeabilized with $0.2 \%$ Triton X-100 in PBS for $10 \mathrm{~min}$. The permeabilized cells were then washed in PBS twice and treated with 5\% normal horse serum in PBS for $30 \mathrm{~min}$ (to minimize the non-specific adsorption of antibodies), before being incubated with anti-slug (1:300) antibody at $4^{\circ} \mathrm{C}$ overnight. Next, the cells were incubated for $1 \mathrm{~h}$ with goat anti-rabbit $\mathrm{IgG}$ antibody conjugated to Alexa 488 dye (Molecular Probes Inc., Tokyo, Japan), while nuclear staining was performed using 4', 6-diamidino-2-phenylindole (DAPI). The cells were visualized using confocal laser scanning microscopy (Zeiss, LSM 710, Wetzlar, Germany). 
Table I. Immunohistochemical expression of DEC2 proteins in human pancreatic cancer tissues.

\begin{tabular}{rlllc}
\hline & & & \multicolumn{2}{c}{ DEC2 } \\
\cline { 4 - 5 } $\mathrm{C}$ & $\mathrm{N} / \mathrm{G}$ & $\mathrm{D}$ & $\mathrm{T}$ & $\mathrm{N}$ \\
\hline 1 & $66 / \mathrm{F}$ & Moderately & Weak & Strong \\
2 & $62 / \mathrm{M}$ & Moderately & Weak & Strong \\
3 & $66 / \mathrm{F}$ & Moderately & Weak & Strong \\
4 & $66 / \mathrm{M}$ & Moderately & Weak & Strong \\
5 & $67 / \mathrm{F}$ & Moderately & Weak & Strong \\
6 & $62 / \mathrm{F}$ & Moderately & Weak & Strong \\
7 & $75 / \mathrm{M}$ & Moderately & Weak & Strong \\
8 & $58 / \mathrm{M}$ & Moderately & Weak & Strong \\
9 & $65 / \mathrm{M}$ & Moderately & Weak & Strong \\
10 & $72 / \mathrm{F}$ & Mell & Weak & Strong \\
11 & $67 / \mathrm{M}$ & Poorly & Weak & Strong \\
12 & $71 / \mathrm{F}$ & Well & Weak & Weak \\
13 & $74 / \mathrm{M}$ & Moderately & Weak & Strong \\
14 & $72 / \mathrm{M}$ & Poorly & Weak & Strong \\
15 & $55 / \mathrm{M}$ & Moderately & Weak & Strong \\
16 & $61 / \mathrm{F}$ & Moderately & Weak & Strong \\
17 & $50 / \mathrm{F}$ & Moderately & Weak & Strong \\
\hline
\end{tabular}

$\mathrm{C}$, cases; A/G, age (years)/gender; D, differentiation of pancreatic cancer; T, tumor cells; $\mathrm{N}$, adjacent non-tumor cells.

Invasion and migration assay. The invasion assay was performed using a BD BioCoat Matrigel invasion chamber kit (BD Biosciences, Franklin Lakes, NJ, USA). BxPC-3 cells were separated using cell dissociation solution (Sigma) and then $\left(5 \times 10^{4}\right.$ cells $\left./ 600 \mu 1\right)$ were added to the top chamber of a cell culture insert in a 24 -well companion plate. After overnight incubation, the cells that had invaded the lower surface of the membrane were fixed with methanol and subjected to Giemsa staining. The number of cells that had migrated was quantified by counting them in ten distinct randomly chosen fields using a light microscope. For the migration assay, BxPC-3 cells were seeded in a 4-chamber slide glass and an artificial 'wound' was carefully created at $0 \mathrm{~h}$ by scratching the confluent cell monolayer with the tip of a P-200 pipette. Microphotographs were taken at 0,24 and $48 \mathrm{~h}$.

Human pancreatic tissues. We performed an immunohistochemical analysis of 17 surgically resected pancreatic tumors, which had been stored at Hirosaki University Hospital, Japan (Table I). All of the 17 tumors had been diagnosed as invasive ductal carcinoma of the pancreas. The histological specimens were retrieved from the archives of our hospital according to the guidelines produced by the Japanese Society of Pathology. We examined the immunohistochemical expression of DEC2 protein in the cancer tissues and the adjacent non-cancerous tissues.

Immunohistochemistry. The expression of DEC2 in the pancreatic cancer tissues was examined in serial deparaf- finized sections and was detected using the Dako EnVision kit/HRP (DAB) (DakoCytomation, Kyoto, Japan). Sections were pretreated with LAB solution (Polysciences, Eppelheim, Germany) for 6 min for antigen retrieval and were incubated overnight at $4{ }^{\circ} \mathrm{C}$ with anti-DEC2 (1:100) (20) antibody diluted in Can Get Signal Immunostain Solution. The sections were then treated with the HRP-conjugated secondary antibody. Finally, the sections were counterstained with Mayer's hematoxylin.

\section{Results}

DEC2 expression is induced in BxPC-3 cells by TGF- $\beta$. In this study, we used human pancreatic cancer BxPC-3 cells to functionally analyze DEC2 and investigate the protein expression of endogenous DEC2 and various EMT-related factors during TGF- $\beta$ treatment. In these cells, TGF- $\beta$ treatment induced Smad3 phosphorylation and upregulated the expression of DEC1, DEC2, slug and vimentin and downregulated the expression of claudin-1 (Fig. 1A). The highest DEC2 expression level was observed in the cells treated with $10 \mathrm{ng} / \mathrm{ml}$ of TGF- $\beta$ for $24 \mathrm{~h}$. TGF- $\beta$ had little effect on the expression of Smad3, snail, E-cadherin, claudin-4 and N-cadherin. Next, we investigated the endogenous mRNA expression of DEC1 and DEC2 in the presence of TGF- $\beta$ using real-time and RT-PCR. The mRNA expression levels of DEC1 and DEC2 were upregulated by TGF- $\beta$ (Fig. 1B).

Since DEC2 has five CAGAC Smad3 binding elements (SBE) in its promoter, we investigated whether Smad3 binds to the SBE in the DEC2 gene. We selected a Smad3 binding target sequence containing a single SBE, which was located near to the transcription starting point of the DEC2 gene (Fig. 1C). The binding of Smad3 to the SBE in the DEC2 promoter was significantly increased in the TGF- $\beta$ treated cells compared with the non-TGF- $\beta$ treated cells.

DEC2 negatively regulates slug expression. To clarify the biological functions of DEC2 in TGF- $\beta$-induced tumor progression, we examined whether the transfection of DEC2 siRNA altered the expression of EMT-related factors. In the presence of TGF- $\beta$, DEC 2 siRNA upregulated the expression of DEC1 and slug, whereas it had little effect on the Smad3 phosphorylation and the expression of Smad3, claudin-1 and vimentin (Fig. 2A and B). The inhibitory effect of DEC 2 knockdown by siRNA in the absence or presence of TGF- $\beta$ was about $60 \%$. In the absence of TGF- $\beta$, DEC2 siRNA transfection had little effect on the expression of DEC1, Smad3, slug, claudin-1 and vimentin and Smad3 phosphorylation. We further examined whether DEC2 overexpression affects the expression of slug by transiently transfecting the cells with a DEC2 expressing plasmid. As a result, we found that in the presence of TGF- $\beta$, the addition of the DEC2 pcDNA decreased the expression of slug compared with the control pcDNA (Fig. 2C).

Using immunofluorescence analysis, we examined whether DEC2 siRNA affects the nuclear/cytoplasmic amounts of slug. As shown in Fig. 2D, DEC2 siRNA significantly increased the nuclear concentration of slug in the presence of TGF- $\beta$. Since the slug gene has one CACGTG E-box element in its promoter, we investigated whether DEC2 binds to this E-box. In the presence of TGF- $\beta$, the addition of control siRNA significantly increased the binding of DEC2 to the slug promoter CACGTG 

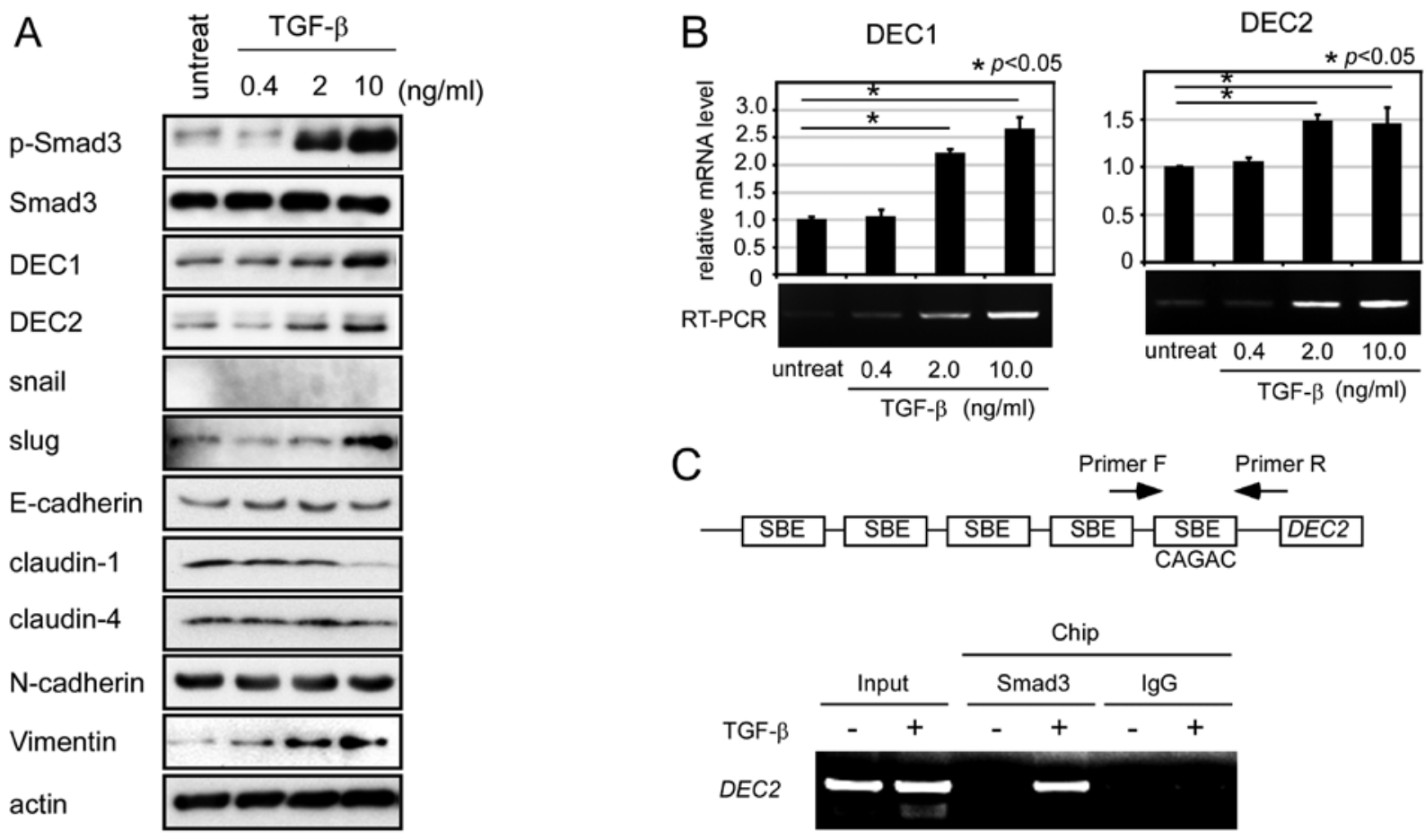

Figure 1. TGF- $\beta$-induced upregulation of DEC2 expression in human pancreatic cancer BxPC-3 cells. (A) BxPC-3 cells were treated with various concentrations of TGF- $\beta$ for $24 \mathrm{~h}$. The cells were then lysed and their lysates were subjected to western blot analyses of pSmad3, Smad3, DEC1, DEC2, snail, slug, E-cadherin, claudin-1, claudin-4, N-cadherin, vimentin and actin. One representative of at least three independent experiments with similar results is shown. (B) BxPC-3 cells were treated as above and total-RNA was prepared and subjected to real-time and RT-PCR for DEC1 and DEC2. Each value represents the mean $\pm \mathrm{SE}$ (bars) of three independent experiments. " $\mathrm{p}<0.05$, according to the $\mathrm{t}$-test. (C) A ChIP assay was performed using BxPC-3 cells that had been treated with or without TGF- $\beta$ (10 ng/ml) for $24 \mathrm{~h}$. The eluted DNA fragments were subjected to PCR. Anti-rabbit IgG was used as an immunoprecipitation control.

E-box compared with that observed after DEC2 siRNA transfection, whereas in the absence of TGF- $\beta$, control siRNA only slightly increased the binding of DEC2 to the slug promoter CACGTG E-box compared with DEC2 siRNA (Fig. 2E).

DEC2 overexpression inhibits the invasion and migration induced by TGF- $\beta$. Migration and invasion are important phenomena in tumor progression. Thus we examined whether DEC2 is involved in invasion and migration. We performed an invasion assay in which we transiently transfected the cells with a DEC1- or DEC2-expressing plasmid. As a result, we found that in the presence of TGF- $\beta$, the number of pcDNAtransfected invasive BxPC-3 cells was increased $\sim 32$-fold compared with the number of pcDNA-transfected cells observed in the absence of TGF- $\beta$ (Fig. 3A). In the presence of TGF- $\beta$, the number of invasive DEC1 pcDNA-transfected cells was increased about 4-fold compared with the number of pcDNA-transfected cells and the number of invasive DEC2 pcDNA-transfected cells was decreased about 4-fold compared with the number of invasive pcDNA-transfected control cells. We also found that in the presence of TGF- $\beta$, DEC2 pcDNA delayed cell migration for $24 \mathrm{~h}$ compared with that observed in the cells transfected with the pcDNA (Fig. $3 \mathrm{~B})$. On the other hand, in the presence of TGF- $\beta$, DEC2 siRNA increased the amount of migration detected at $24 \mathrm{~h}$ compared with that observed in the cells transfected with control siRNA.

DEC2 protein expression in human pancreatic cancer tissues and the adjacent non-cancerous pancreatic tissues. We exam- ined the immunohistochemical expression of DEC2 in human pancreatic cancer tissues. Photographs of the DEC2 expression in representative cases are shown in Fig. 4. Significant DEC2 immunoreactivity was detected in the non-cancerous pancreatic tissues (94\%; 16/17 cases) compared with the adjacent cancer tissues and it was predominantly localized within the cytoplasm of the non-cancerous pancreatic cells, although very weak DEC2 immunoreactivity was found in the adjacent cancer cells in all cases.

\section{Discussion}

DEC2 regulates apoptosis, the response to hypoxia, differentiation and circadian rhythms $(16-18,20,23)$. However, the role of DEC2 in tumor progression is poorly understood. Epithelial mesenchymal transition (EMT) is characterized by the loss of epithelial factors and upregulated mesenchymal marker expression and results in a spindle cell morphology and invasive phenotype $(3,8)$. We showed that TGF- $\beta$ increased the migration and invasion of BxPC-3 cells and upregulated their DEC2 expression. In addition, TGF- $\beta$ affected the levels of some EMT-related molecules, such as p-Smad3, slug, claudin-1 and vimentin, although it had little effect on the expression of snail, claudin-4, E-cadherin and N-cadherin and the cell morphology. Nishioka et al (24) also found that TGF- $\beta$ had little effect on the expression of E-cadherin and the cell morphology in BxPC-3 cells. These results suggest that TGF- $\beta$ upregulates the malignancy of BxPC- 3 cells by increasing their migration and invasion and upregulating their slug expression, but does not affect the EMT. 

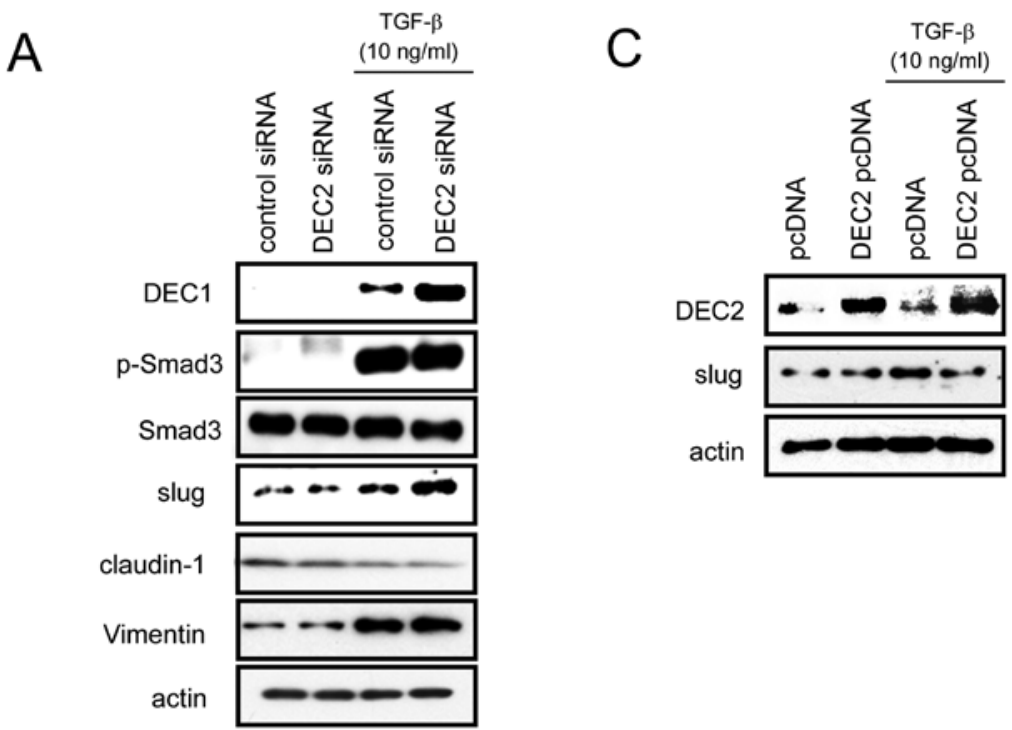

B
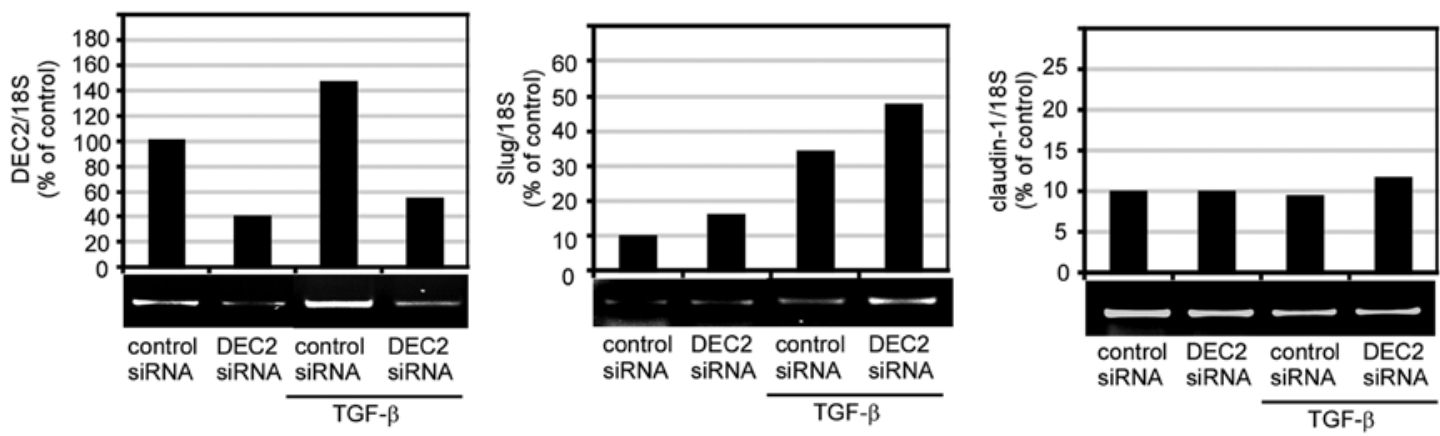

$\mathrm{D}$

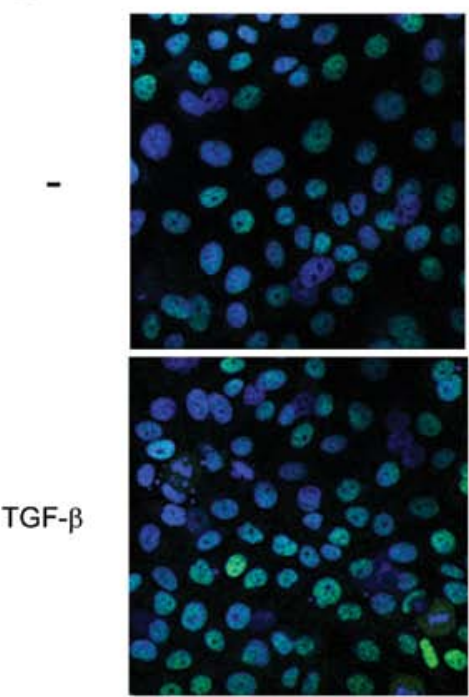

DEC2 siRNA

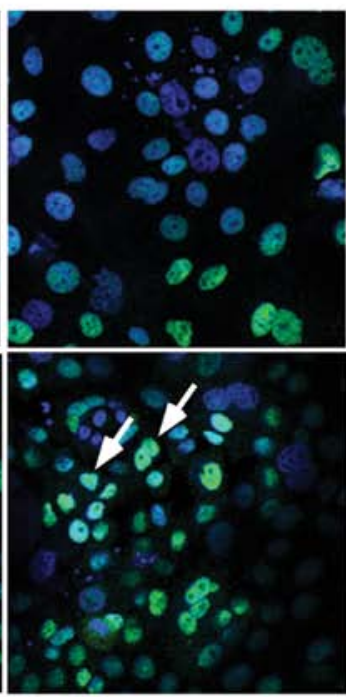

$E$

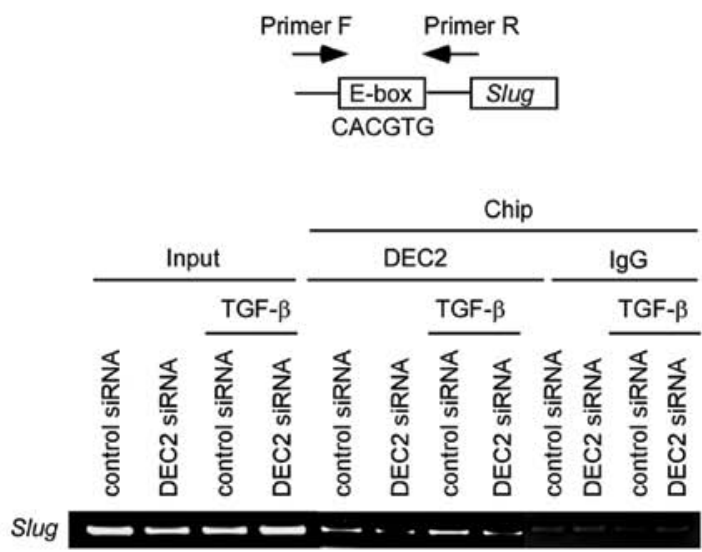

Figure 2. DEC2 negatively regulates slug. (A) BxPC-3 cells were transfected with control siRNA or siRNA against DEC2. At $24 \mathrm{~h}$ post-transfection, the cells were treated with TGF- $\beta(10 \mathrm{ng} / \mathrm{ml})$ and incubated for $24 \mathrm{~h}$ and their lysates were subjected to western blot analyses of DEC1, pSmad3, Smad3, slug, claudin-1, vimentin and actin. One representative of at least three independent experiments with similar results is shown. (B) BxPC-3 cells were treated as above and total-RNA was prepared and subjected to real-time and RT-PCR for DEC2, slug and claudin-1. Each value represents the mean \pm SE (bars) of three independent experiments. " $\mathrm{p}<0.05$, according to the t-test. (C) BxPC-3 cells were transfected with pcDNA or DEC2 pcDNA. At $24 \mathrm{~h}$ post-transfection, the cells were treated with or without TGF- $\beta(10 \mathrm{ng} / \mathrm{ml})$ for $24 \mathrm{~h}$ and their lysates were subjected to western blot analyses of DEC2, slug and actin. (D) BxPC-3 cells were treated as above and the cells were fixed, incubated with anti-slug antibody and visualized using Alexa488-conjugated secondary antibody (green). The cells were also counterstained with DAPI (blue) in order to detect their nuclei. A merged image that is representative of at least two independent experiments with similar results is shown. The arrows indicate strong colocalized amounts. (E) BxPC-3 cells were transfected with control siRNA or siRNA against DEC2. At $24 \mathrm{~h}$ posttransfection, a ChIP assay was performed using BxPC-3 cells that had been treated with or without TGF- $\beta$ (10 ng/ml) for $24 \mathrm{~h}$. PCR was performed as above. 
A

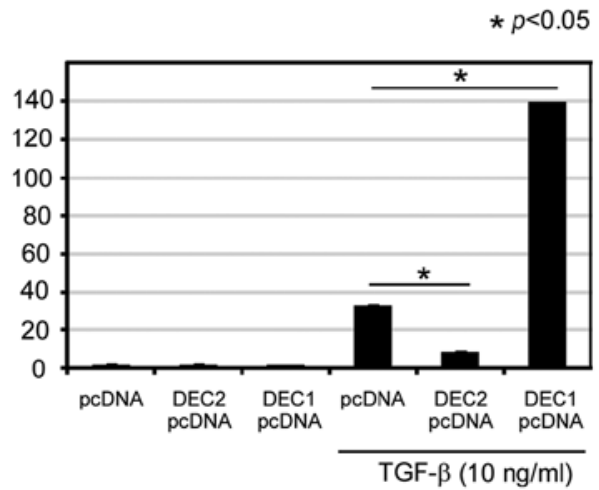

B
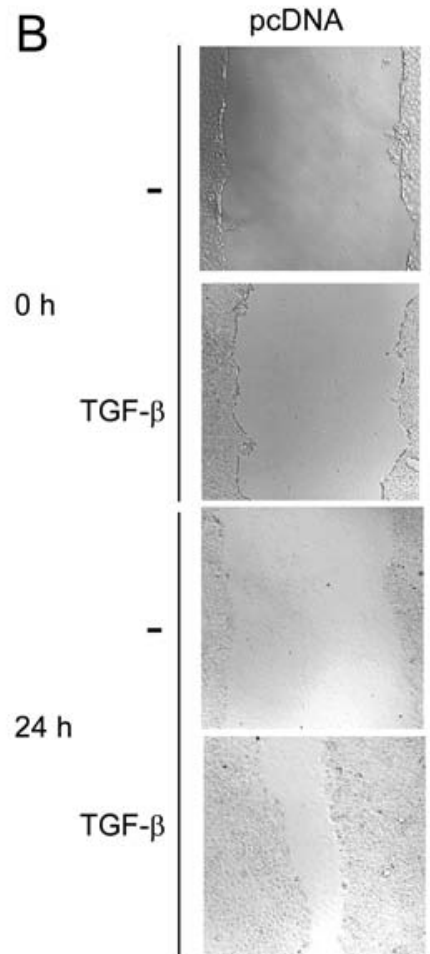

control siRNA

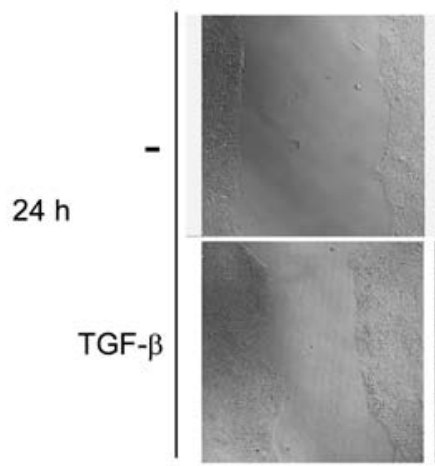

DEC2 pcDNA
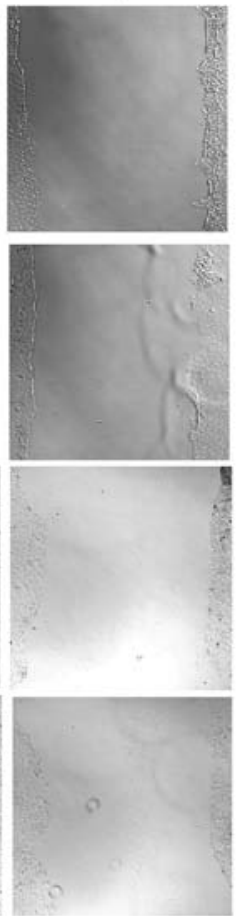

DEC2 SiRNA

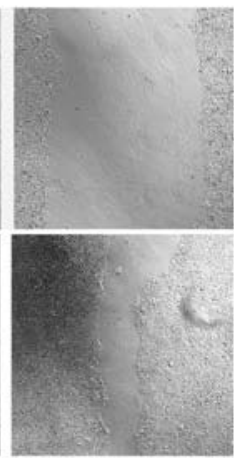

Figure 3. DEC2 overexpression decreases the invasion and migration induced by TGF- $\beta$. (A) BxPC-3 cells were transfected with pcDNA, DEC1 pcDNA or DEC2 pcDNA. At $24 \mathrm{~h}$ post-transfection, the cells were treated with or without TGF- $\beta(10 \mathrm{ng} / \mathrm{ml})$ for $24 \mathrm{~h}$ and $5 \times 10^{4}$ cells each were seeded in an invasion chamber. At $24 \mathrm{~h}$ after cell seeding, the chambers were stained and the number of invasive cells was counted. The panel shows quantitative data. Each value represents the mean $\pm \mathrm{SE}$ (bars) of three independent experiments. " $\mathrm{p}<0.05$, according to the t-test. (B) BxPC-3 cells were transfected pcDNA or DEC2 pcDNA as described above. In addition, the cells were transfected with control or DEC2 siRNA with or without TGF- $\beta$ (10 ng/ml). After 24-h TGF- $\beta$ treatment, a wound was made with a pipette tip and photographs of the wounded area were taken periodically. One representative of at least three independent experiments with similar results is shown.

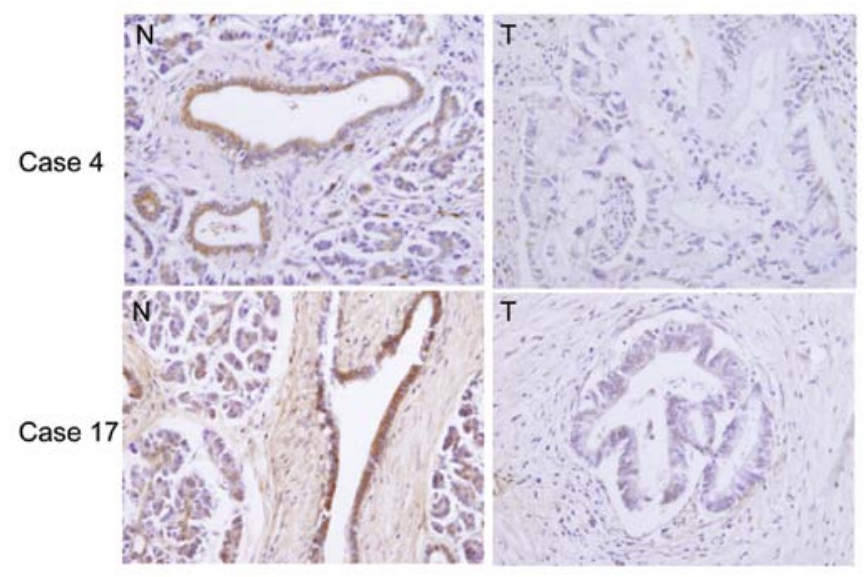

Figure 4. DEC2 expression is decreased in human pancreatic cancer tissues. (panel N) Significant DEC2 immunoreactivity was detected in the non-cancerous pancreatic tissues, (panel $\mathrm{T}$ ) whereas it was weak in the pancreatic cancer tissues (cases 4 and 17 involved moderately differentiated adenocarcinoma).

We found that Smad3 binds to the SBE in the DEC2 promoter. These findings suggest that TGF- $\beta$ and Smad3 are upstream factors of DEC2. It was reported that TGF- $\beta$ increases the expression and promoter activities of snail and slug in various cancer cells (25-27). Transcription factors snail and slug play important roles in TGF- $\beta$-induced tumor progression and have E-boxes in their promoters $(28,29)$. However, snail was not upregulated by TGF- $\beta$ in the BxPC-3 cells. Thus, we focused on the effects of DEC2 on slug. Slug enhances invasion in various cancer cells, involving upregulation of metalloproteinase-9 and downregulation of E-cadherin $(30,31)$. Slug also enhances proliferation and migration in prostate and ovarian cancer cells $(32,33)$. We showed that DEC2 knockdown or overexpression in the presence of TGF- $\beta$ affected both the expression and the nuclear concentration of slug. In addition, DEC2 bound to the E-box in the slug promoter. These findings suggest that DEC2 negatively regulates slug through its E-box. We also showed that DEC2 inhibits the expression of DEC1, as previously described (34), as well as the migration and invasion induced by TGF- $\beta$. DEC1 is highly expressed in various tumors $(21,35-37)$, whereas DEC2 is highly expressed in non-cancerous pancreatic ducts compared with cancer tissues. DEC2 also negatively regulates DEC1 through its E-box (34). Based on the above findings, DEC2 may inhibit tumor progression by suppressing slug or DEC1. Further studies are needed to clarify the details of the mechanism by which $\mathrm{DEC1}$ regulates slug.

In the present study, we demonstrated that DEC2 inhibits TGF- $\beta$-induced tumor progression through slug in BxPC-3 cells and DEC2 is expressed at relatively low levels in cancer tissues compared with its levels in non-cancerous tissues. Further studies are needed to clarify the role of DEC2 in the effects induced by TGF- $\beta$ and to elucidate the detailed molecular mechanisms by which DEC2 inhibits tumor progression.

\section{Acknowledgements}

This study was supported by Grants-in-Aid for Science from the Ministry of Education, Culture, Sports, Science, and Technology 
of Japan; a Grant for Hirosaki University Institutional Research; and the Fund for the Promotion of International Scientific Research.

\section{References}

1. Jemal A, Siegel R, Ward E, Murray T, Xu J, Smigal C and Thun MJ: Cancer statistics, 2006. CA Cancer J Clin 56: 106-130, 2006.

2. Yeo TP, Hruban RH, Leach SD, Wilentz RE, Sohn TA, Kern SE, Iacobuzio-Donahue CA, Maitra A, Goggins M, Canto MI, et al: Pancreatic cancer. Curr Probl Cancer Rev 26: 176-275, 2002.

3. Zavadil $\mathrm{J}$ and Böttinger EP: TGF-beta and epithelial-to-mesenchymal transitions. Oncogene 24: 5764-5774, 2005.

4. Miettinen PJ, Ebner R, Lopez AR and Derynck R: TGF-beta induced transdifferentiation of mammary epithelial cells to mesenchymal cells: involvement of type I receptors. J Cell Biol 127: 2021-2036, 1994.

5. Kleeff J, Friess H, Simon P, Susmallian S, Büchler P, Zimmermann A, Büchler MW and Korc M: Overexpression of Smad 2 and colocalization with TGF-beta1 in human pancreatic cancer. Dig Dis Sci 44: 1793-1802, 1999.

6. Friess H, Yamanaka Y, Büchler M, Ebert M, Beger HG, Gold LI and Korc M: Enhanced expression of transforming growth factor beta isoforms in pancreatic cancer correlates with decreased survival. Gastroenterology 105: 1846-1856, 1993.

7. Huber MA, Kraut N and Beug H: Molecular requirements for epithelial-mesenchymal transition during tumor progression. Curr Opin Cell Biol 17: 548-558, 2005.

8. Thiery JP and Sleeman JP: Complex networks orchestrate epithelial-mesenchymal transitions. Nat Rev Mol Cell Biol 7: 131-142, 2006

9. Medici D, Hay ED and Olsen BR: Snail and Slug promote epithelial-mesenchymal transition through beta-catenin-T-cell factor-4-dependent expression of transforming growth factorbeta 3. Mol Biol Cell 19: 4875-4887, 2008.

10. Hahn SA, Schutte M, Hoque AT, Moskaluk CA, da Costa LT, Rozenblum E, Weinstein CL, Fischer A, Yeo CJ, Hruban RH and Kern SE: DPC4, a candidate tumor suppressor gene at human chromosome 18q21.1. Science 271: 350-353, 1996.

11. Bartsch D, Hahn SA, Danichevski KD, Ramaswamy A, Bastian D, Galehdari H, Barth P, Schmiegel W, Simon B and Rothmund M: Mutations of the DPC4/Smad4 gene in neuroendocrine pancreatic tumors. Oncogene 18: 2367-2371, 1999.

12. Miyazawa K, Shinozaki M, Hara T, Furuya T and Miyazono K: Two major Smad pathways in TGF-beta superfamily signalling. Genes Cells 7: 1191-1204, 2002.

13. Massagué J: How cells read TGF-beta signals. Nat Rev Mol Cell Biol 1: 169-178, 2000

14. Zawel L, Dai JL, Buckhaults P, Zhou S, Kinzler KW, Vogelstein B and Kern SE: Human Smad3 and Smad4 are sequence-specific transcription activators. Mol Cell 1: 611-617, 1998.

15. Sato F, Kawamoto T, Fujimoto K, Noshiro M, Honda KK, Honma S, Honma K and Kato Y: Functional analysis of the basic helix-loop-helix transcription factor DEC1 in circadian regulation. Interaction with BMAL1. Eur J Biochem 271: 4409-4419, 2004.

16. Sato F, Bhawal UK, Kawamoto T, Fujimoto K, Imaizumi T, Imanaka T, Kondo J, Koyanagi S, Noshiro M, Yoshida $\mathrm{H}$, et al: Basic-helix-loop-helix (bHLH) transcription factor DEC2 negatively regulates vascular endothelial growth factor expression. Genes Cells 13: 131-144, 2008.

17. Wu Y, Sato F, Bhawal UK, Kawamoto T, Fujimoto K, Noshiro M, Morohashi S, Kato Y and Kijima H: Basic helix-loop-helix transcription factors DEC1 and DEC2 regulate the paclitaxelinduced apoptotic pathway of MCF-7 human breast cancer cells. Int J Mol Med 27: 491-495, 2011.

18. Wu Y, Sato F, Bhawal UK, Kawamoto T, Fujimoto K, Noshiro M, Seino H, Morohashi S, Kato Y and Kijima H: BHLH transcription factor DEC2 regulates pro-apoptotic factor Bim in human oral cancer HSC-3 cells. Biomed Res 33: 75-82, 2012.

19. Imaizumi T, Sato F, Tanaka H, Matsumiya T, Yoshida H, YashiroAizawa T, Tsuruga K, Hayakari R, Kijima H and Satoh K: Basic-helix-loop-helix transcription factor DEC2 constitutes negative feedback loop in IFN- $\beta$-mediated inflammatory responses in human mesangial cells. Immunol Lett 136: 37-43, 2011.
20. Liu Y, Sato F, Kawamoto T, Fujimoto K, Morohashi S, Akasaka H, Kondo J, Wu Y, Noshiro M, Kato Y and Kijima H: Anti-apoptotic effect of the basic helix-loop-helix (bHLH) transcription factor DEC2 in human breast cancer cells. Genes Cells 15: 315-325, 2010.

21. Bhawal UK, Sato F, Arakawa Y, Fujimoto K, Kawamoto T, Tanimoto K, Ito Y, Sasahira T, Sakurai T, Kobayashi M, et al: Basic helix-loop-helix transcription factor DEC1 negatively regulates cyclin D1. J Pathol 224: 420-429, 2011.

22. Sato F, Wu Y, Bhawal UK, Liu Y, Imaizumi T, Morohashi S, Kato Y and Kijima H: PERIOD1 (PER1) has anti-apoptotic effects, and PER3 has pro-apoptotic effects during cisplatin (CDDP) treatment in human gingival cancer CA9-22 cells. Eur J Cancer 47: 1747-1758, 2011.

23. Choi SM, Cho HJ, Cho H, Kim KH, Kim JB and Park H: Stra13/ DEC1 and DEC2 inhibit sterol regulatory element binding protein-1c in a hypoxia-inducible factor-dependent mechanism. Nucleic Acids Res 36: 6372-6385, 2008.

24. Nishioka R, Itoh S, Gui T, Gai Z, Oikawa K, Kawai M, Tani M, Yamaue $\mathrm{H}$ and Muragaki Y: SNAIL induces epithelial-to-mesenchymal transition in a human pancreatic cancer cell line (BxPC3) and promotes distant metastasis and invasiveness in vivo. Exp Mol Pathol 89: 149-157, 2010.

25. Shah PP and Kakar SS: Pituitary tumor transforming gene induces epithelial to mesenchymal transition by regulation of twist, snail, slug, and E-cadherin. Cancer Lett 311: 66-76, 2011.

26. Takano S, Kanai F, Jazag A, Ijichi H, Yao J, Ogawa H, Enomoto N, Omata M and Nakao A: Smad4 is essential for down-regulation of E-cadherin induced by TGF-beta in pancreatic cancer cell line PANC-1. J Biochem 141: 345-351, 2007.

27. Thuault S, Valcourt U, Petersen M, Manfioletti G, Heldin CH and Moustakas A: Transforming growth factor-beta employs HMGA2 to elicit epithelial-mesenchymal transition. J Cell Biol 174: 175-183, 2006.

28. Sánchez-Martín M, Rodríguez-García A, Pérez-Losada J, Sagrera A, Read AP and Sánchez-García I: SLUG (SNAI2) deletions in patients with Waardenburg disease. Hum Mol Genet 11: 3231-3236, 2002.

29. Grotegut S, von Schweinitz D, Christofori G and Lehembre F: Hepatocyte growth factor induces cell scattering through MAPK/ Egr-1-mediated upregulation of Snail. EMBO J 25: 3534-3545, 2006.

30. Zhang K, Chen D, Jiao X, Zhang S, Liu X, Cao J, Wu L and Wang D: Slug enhances invasion ability of pancreatic cancer cells through upregulation of matrix metalloproteinase- 9 and actin cytoskeleton remodeling. Lab Invest 91: 426-438, 2011.

31. Tang P, Yu Z, Zhang K, Wang Y, Ma Z, Zhang S, Chen D and Zhou Y: Slug down-regulation by RNA interference inhibits invasion growth in human esophageal squamous cell carcinoma. BMC Gastroenterol 11: 60, 2011.

32. Emadi Baygi M, Soheili ZS, Essmann F, Deezagi A, Engers R, Goering W and Schulz WA: Slug/SNAI2 regulates cell proliferation and invasiveness of metastatic prostate cancer cell lines. Tumour Biol 31: 297-307, 2010.

33. Kurrey NK, Amit K and Bapat SA: Snail and Slug are major determinants of ovarian cancer invasiveness at the transcription level. Gynecol Oncol 97: 155-165, 2005.

34. Kawamoto T, Noshiro M, Sato F, Maemura K, Takeda N, Nagai R, Iwata T, Fujimoto K, Furukawa M, Miyazaki K, et al: A novel autofeedback loop of Dec1 transcription involved in circadian rhythm regulation. Biochem Biophys Res Commun 2: 117-124, 2004.

35. Chakrabarti J, Turley H, Campo L, Han C, Harris AL, Gatter KC and Fox SB: The transcription factor DEC1 (stra13, SHARP2) is associated with the hypoxic response and high tumour grade in human breast cancers. Br J Cancer 91: 954-958, 2004.

36. Giatromanolaki A, Koukourakis MI, Sivridis E, Turley H, Wykoff CC, Gatter KC and Harris AL: DEC1 (STRA13) protein expression relates to hypoxia-inducible factor 1-alpha and carbonic anhydrase-9 overexpression in non-small cell lung cancer. J Pathol 200: 222-228, 2003.

37. Li Y, Zhang H, Xie M, Hu M, Ge S, Yang D, Wan Y and Yan B: Abundant expression of Dec1/stra13/sharp2 in colon carcinoma: its antagonizing role in serum deprivation-induced apoptosis and selective inhibition of procaspase activation. Biochem J 367: 413-422, 2002. 